\title{
METAFORA PENGUNGKAP KECANTIKAN DALAM MASYARAKAT MADURA
}

\author{
Nur Awaliyah Putri \\ Magister Ilmu Linguistik, Fakultas Ilmu Budaya, Universitas Gadjah Mada \\ nurawaliyah1807@gmail.com
}

\begin{abstract}
This paper describes the metaphors in Madurese used for expressing women's beauty, and the Madurese people's prespective about women's beauty through those metaphors. Library reasearch was conducted to obtain the data. The library research refers to the use of books containing the list of metaphors used by Madurese people to express women's beauty. An old Madurese dictionary was also used for translating some old words found and which were no longer used in daily communication. In addition, the writer also read some references about Madurese culture to elicit more information about Madurese cultural values and practices, especially that are related to the objects used for those metaphors. Referential comparation method with classifying technique was used for analyzing the data. The data were classified based on their reference. Afterwards, the writer compared the object used in the metaphors, and the woman's physic and behaviour. The results showed that there were 49 metaphors in Madurese used for expressing women's beauty which consisted of 39 metaphors for women's physical beauty, and 10 metaphors for behavioural beauty. The objects compared in the metaphors included plants, equipments, animals, food, and nature. The metaphors reflect the Madurese people's prespectives about women's beauty; which are: 1) women's physical beauty is easier to be expressed in metaphor than the behavioural one; 2) woman's behavioural beauty is very important; 3) there are more than one ideal shape of some particular women's body parts; and 4) plant is a high source of life, culture and practice value in Madurese society.
\end{abstract}

Keywords:Madurese, Metaphor, Linguistics Anthropology, Women's beauty

\section{PENDAHULUAN}

Cara pandang masyarakat dapat terlihat dari bagaimana masyarakat tersebut mengungkapkan suatu konsep dalam kehidupan. Salah satunya adalah cara pandang masyarakat terhadap konsep kecantikan perempuan, baik itu kecantikan secara lahir maupun batin. Dewasa ini, kecantikan perempuan merupakan suatu hal yang banyak mendapat perhatian dan hal ini dibuktikan dengan banyaknya acara-acara televisi, tulisan, dan lain sebagainya yang membahas tentang perempuan cantik. Wolf (2002) menyatakan bahwa ada perasaan khawatir dalam diri perempuan-perempuan saat ini terkait keadaan fisiknya hingga kehawatiran tersebut jauh lebih besar dibandingkan kekhawatiran generasi-generasi perempuan sebelumnya. Tolak ukur tentang perempuan cantik atau konsep kecantikan perempuan baik itu secara lahir maupun 
batin membuat suatu masyarakat budaya memiliki ungkapan-ungkapan khusus terkait hal tersebut. Ungkapan-ungkapan tersebut, kemudian, mampu mencerminkan cara pandang masyarakat tentang konsep kecantikan itu sendiri. Salah satu masyarakat yang mempunyai ungkapan-ungkapan terhadap kecantikan perempuan adalah masyarakat Madura. Banyak yang tidak mengetahui bahwa masyarakat Madura memiliki ungkapan-ungkapan terkait konsep kecantikan karena kecantikan dan perempuan selalu dikaitkan dan digambarkan dengan nilai estetika dan suatu simbol pembawa keindahan yang mengandung makna kehalusan, keanggunan, ketabahan, kesantunan dan kelembutan (Tilaar, 1999; Tim, 2004). Sementara itu, dengan kontras, masyarakat luar mengaitkan masyarakat Madura, baik secara lahir dan batin, dengan stereotipe negatif. Secara lahiriah, masyarakat Madura digambarkan dengan masyarakat yang laki-lakinya kekar, berotot, bermuka lebar, kasar dan tidak halus, memiliki tulang pipi yang menonjol dan wajah yang galak; dan perempuannya memiliki struktur tulang yang kasar dan raut muka yang terlalu tebal (van Gennep dalam de Jonge, 2011). Kemudian, secara batiniah atau secara sikap, masyarakat Madura digambarkan sebagai masyarakat yang keras, mudah marah dan tersinggung, pendendam, selalu curiga, kasar, arogan, egois, kurang sopan, gugup, keras kepala, berdarah panas, beringas, suka berkelahi dan bengis; serta perempuannya juga tidak terlalu anggun dan berwibawa (Boswa dalam Karim, 2004; de Jonge, 2011; Royce dan Tim Peneliti UNAIR dalam Setiadi, 2005; Setiadi, 2005).

Stereotip-stereotip di atas tidak sepenuhnya benar, karena masyarakat Madura juga memiliki sikap yang ramah, mempertahankan prinsip, memiliki rasa kekeluargaan dan kekerabatan yang tinggi, menjunjung tinggi harga diri dan kehormatan, santun dan menghormati sesepuh dan leluhur (Zawawi dalam Karim, 2004). Stereotip-stereotip di atas juga kemudian membuat masyarakat di luar masyarakat Madura yang tidak tahu bahwa masyarakat Madura memiliki ungkapan-ungkapan dalam bentuk metaforametafora terkait konsep kecantikan perempuan yang dikaitkan dengan kehalusan, keanggunan, ketabahan, kesantunan dan kelembutan. Secara umum, perempuan cantik Madura diibaratkan sebagai Raden Ayu Potré Konéng atau Raden Ayu Putri Kuning. Raden Ayu Potré Konéng adalah ibu dari Pangeran Jokotole, Raja Sumenep ke-13 yang dibawah kepemimpinannya mampumembawa Sumenep ke puncak kejayaan. Selain merupakan ibu dari Pangeran Jokotole, Raden Ayu Potré Konéng dikenal akan kecantikan paras, fisik, dan sikap yang kemudian menjadi sosok ideal perempuan cantik Madura. Namun, sosok ideal perempuan Madura juga diungkapkan secara lebih rinci, misalnya matanya, rambutnya, cara berjalan, dan cara melirik, melalui metafora. Hal yang menunjukkan penggunaan metafora-metafora pengungkap konsep kecantikan perempuan dalam masyarakat Madura ada pada lirik lagu Potre Madhura 
yang merupakan salah satu lagu daerah Madura. Misalnya, cara melambai perempuan Madura yang indah diungkapkan dengan metafora meltas manjhâlin atau secara harfiah berarti kayu rotan yang elastis, dan cara berjalannya yang indah diungkapkan dengan metafora nétér kolénang yang secara harfiah berarti alunan bonang. Penggunaan metafora-metafora pengungkap konsep kecantikan perempuan dalam masyarakat Madura juga muncul di acara pernikahan, pemilihan duta wisata, dan lain-lain sebagai bentuk pujian terhadap individu yang dibicarakan. Konsep kecantikan perempuan, baik secara lahir maupun batin itu diungkapkan dalam bentuk metafora-metafora yang mampu mencerminkan cara pandang masyarakat Madura.

Penelitian yang membahas metafora pengungkap kecantikan perempuan Madura dan kaitannya dengan cara pandang masyarakat Madura belum pernah dilakukan. Namun, penelitian tentang metafora pengungkap kecantikan perempuan pernah dilakukan sebelumnya. Salah satu penelitian tersebut dilakukan oleh Setyari (2007) untuk tesisnya dengan judul Panyandra bentuk tubuh indah dalam masyarakat Jawa. Penelitian tersebut membahas pembentukan dan faktor-faktor pembentuk istilah dalam nyandra, dan cara pandang masyarakat Jawa yang tercermin melalui panyandra tersebut. Hasilnya menunjukkan bahwa panyandra bentuk tubuh indah perempuan Jawa dipengaruhi oleh lingkungan Jawa yang agragis sehingga banyak digunakan namanama tumbuhan dan alam. Walaupun objek penelitian tersebut sama dengan penelitian peneliti saat ini, yaitu metafora pengungkap kecantikan perempuan, tetapi bahasa yang mewadahi objek tersebut berbeda. Metafora pengungkap kecantikan perempuan pada penelitian sebelumnya merupakan metafora pengungkap kecantikan dalam Bahasa Jawa, sementara penelitian saat ini merupakan metafora pengungkap kecantikan dalam Bahasa Madura. Perbedaan bahasa ini tentu sangat berpengaruh terhadap cara pandang masyarakat terhadap kecantikan perempuan yang akan terungkap karena masyakarat penutur dari dua bahasa ini merupakan masyarakat yang berbeda. Selain itu, penelitian sebelumnya terbatas pada metafora pengungkap kecantikan fisik perempuan saja, sementara penelitian ini tidak hanya mengungkap kecantikan fisik perempuan tetapi juga kecantikan sikap perempuan. Metafora-metafora pengungkap kecantikan perempuan Madura juga disebutkan di beberapa beberapa buku Bahasa Madura atau kosa kata Bahasa Madura. Metafora-metafora tersebut hanya dibahas penggunaannya terhadap anggota tubuh atau sikap perempuan Madura sebagai referensinya tetapi tidak dijelaskan maknanya. Berdasarkan latar belakang masalah dan kurangnya penelitian terkait metafora pengungkap kecantikan masyarakat Madura ini membuat peneliti tertarik meneliti cara pandang masyarakat Madura yang terbaca dari penggunaan metafora pengungkap konsep kecantikan perempuan dalam masyarakat Madura. 


\section{LANDASAN TEORI}

\section{Metafora}

Teori tentang metafora ini digunakan untuk menjawab permasalahan yang pertama yaitu deskripsi metafora pengungkap kecantikan perempuan dalam Masyarakat Madura. Metafora didefinisikan oleh Kridalaksana sebagai perbandingan antara dua hal yang memiliki kemiripan atau kesamaan tanpa adanya penggunaan kata seperti, bagaikan, bagai, bak, ibarat, dan lain-lain (1993: 106). Metafora juga merujuk pada kata atau kumpulan kata bukan dengan arti yang sebenarnya, tetapi dalam bentuk kiasan karena adanya kemiripan atau kesamaan (KBBI, 2016). Sementara itu, oleh Knowles dan Moon (2006: 2), metafora didefinisikan sebagai penggunaan bahasa untuk merujuk kepada hal lain yang memiliki kesamaan atau hubungan antara objek yang ditunjuk dan yang menjadi penunjuk. Dari dua definisi tersebut, metafora memiliki sebuah fungsi dalam komunikasi dimana salah satu fungsinya adalah menyampaikan maksud atau ide tentang kemiripan dua buah hal yang dibandingkan dengan kata-kata dengan makna yang bukan sebenarnya. Hal ini juga menunjukkan bahwa ada beberapa hal yang ada dalam ruang lingkup metafora, yaitu dua hal yang dibandingkan, misalnya A dan B, kesamaan atau kemiripan antara $\mathrm{A}$ dan $\mathrm{B}$, dan bentuk linguistik yang digunakan untuk perbandingan itu. Beberapa hal ini dijelaskan oleh Palmer (1999: 223) sebagai tiga unsur metafora, yang meliputi (a) Tenor.Tenor adalah objek yang dikiaskan atau disebut pebanding; (b) Vehicle. Vehicle atau disebut juga pembanding adalah konsep yang digunakan untuk melambangkan tenor; dan (c) Ground. Ground adalah persamaan yang muncul antara tenor dan vehicle. Contoh aplikasi tiga unsur metafora ini adalah pada metafora raja hutan. Metafora raja hutan mengacu pada singa. Unsur tenor atau pebanding pada metafora ini adalah singa, dimana singa ini adalah objek yang dikiaskan. Raja merupakan vehicle atau pembanding, sementara ground atau persamaan antara tenor dan vehicle ini adalah sifat mampu menguasai suatu domain. Penggunaan metafora dalam komunikasi suatu masyarakat mampu mencerminkan budaya masyarakat tersebut, seperti yang dijelaskan oleh Keesing dalam Duranti (1997: 38) bahwa metafora dianggap sebagai situasi dimana suatu budaya dibawa dalam bentuk linguistik dan digunakan dalam komunikasi. Kemudian, Lakoff dan Jhonson (dalam Duranti, 2007: 65) juga menjelaskan bahwa metafora adalah wadah bagi hubungan antara manusia dan pengalaman dalam hidupnya. Penelitian ini akan dikaji melalui pendekatan semantik kognitif. Menurut Saed (1999: 299), dalam semantik kognitif, persoalan mental menjadi bagian dari makna bahasa.

\section{Bahasa, Budaya dan Pikiran}

Teori ini digunakan untuk mendukung asumsi-asumsi peneliti terkait cara pandang masyarakat Madura yang tercermin dari penggunaan metafora pengungkap 
kecantikan perempuan. Hal ini dilakukan untuk menghindari kesubyektifan peneliti. Bahasa, budaya, dan pikiran memiliki suatu hubungan yang mampu menunjukkan suatu realita dalam kehidupan seseorang. Kramsch (1998: 3), misalnya, menjelaskan bahwa salah satu hubungan penting antara bahasa, budaya, dan pikiran, adalah bahwa bahasa mampu menunjukkan realitas budaya (language expresses cultural reality). Dalam hal ini, gagasan terhadap suatu keadaan atau fakta, pemikiran, cara pandang suatu masyarakat, sikap, kepercayaan bisa disampaikan oleh pengguna bahasa melalui bahasa yang digunakannya. Jika dikaitkan lebih dekat lagi dengan aspek budaya, Boas (dalam Ahearn, 2012: 66) menyatakan bahwa suatu bahasa tertentu yang digunakan oleh suatu masyarakat cenderung mencerminkan praktik-praktik budaya masyarakat itu sendiri. Contohnya, masyarakat Jawa memiliki banyak istilah tentang 'nasi', yaitu pari, gabah, beras, sego, upo, dan karak. Tentu saja ini berbeda dengan konsep 'nasi' yang dimiliki oleh masyarakat Inggris, yang hanya mengenal istilah rice saja. Ini menunjukkan bahwa dalam masyarakat Jawa, ada praktik-praktik budaya yang berkaitan dengan 'nasi' yang lebih kompleks dibandingkan dalam masyarakat Inggris. Banyaknya istilah yang berkaitan dengan 'nasi' dan dilihat dari makna tiap istilahnya, mencerminkan bahwa masyarakat Jawa memiliki praktik-praktik budaya tnetang 'nasi' mulai dari praktik yang berhubungan dengan pertanian hingga pengolahannya. Ahimsa-Putra (1986: 107) juga menambahkan bahwa kita bisa mengetahui dasar penentuan cara pandang suatu masyarakat terhadap konsep kehidupan dari penamaan-penamaan suatu hal dalam ranah tertentu.

\section{METODE PENELITIAN}

Penelitian ini akan dikaji melalui pendekatan semantik kognitif. Menurut Saed (1999: 299), dalam semantik kognitif, persoalan mental menjadi bagian dari makna bahasa. Data dalam penelitian ini terdiri dari data primer dan data sekunder. Data primer merujuk pada daftar metafora pengungkap kecantikan perempuan dalam masyarakat Madura yang ada pada buku-buku Bahasa Madura. Untuk mendapatkan data primer dan sekunder tersebut, peneliti menggunakan metode simak bebas libat cakap dengan teknik rekam dan catat. Dalam metode simak, peneliti menyimak penggunaan bahasa (Sudaryanto, 1988: 2). Sudaryanto juga menjelaskan bahwa membaca buku-buku acuan yang merupakan bentuk teks juga masuk dalam menyimak karena peneliti mengulangi mengucapkan bacaan tersebut (2015: 207). Peneliti juga menggunakan kamus Bahasa Madura kuno yang ditulis oleh H. N. Kiliaan pada tahun 1904 untuk abjad A, E, I, U, O, H, N, C, R, K, D, T, S; dan 1905 untuk abjad W, L, P, D, J, Y, M, G, B, T untuk menerjemahkan kata-kata Bahasa Madura kuno yang tidak lagi digunakan dalam Bahasa Madura saat ini yang digunakan dalam metafora-metafora pengungkap kecantikan perempuan dalam masyarakat Madura. Sementara itu, data sekunder merujuk pada informasi-informasi terkait penggunaan dan 
pandangan masyarakat Madura terhadap metafora pengungkap kecantikan perempuan dalam masyarakat Madura itu sendiri. Untuk mendapatkan data sekunder tersebut, peneliti menggunakan metode simak bebas libat cakap dengan teknik rekam dan catat. Peneliti menyimak buku-buku yang membahas kebudayaan masyarakat Madura, yang berkaitan dengan praktik-praktik dan nilai kebudayaan serta kehidupan dalam masyarakat Madura.

Untuk menganalisis data, peneliti akan menggunakan metode padan referensial dengan teknik daya pilah sebagai pembeda referen dan teknik hubung banding dan menyamakan. Data yang terkumpul dipilah sesuai dengan referennya, yaitu data yang menunjukkan metafora pengungkap kecantikan fisik atau sikap perempuan dalam masyarakat Madura. Dari pemilahan tersebut kemudian peneliti membandingkan dan menyamakan bentuk yang digunakan sebagai metafora dengan referennya, yaitu fisik atau sikap perempuan yang dimetaforakan.Misalnya, duri merupakan bentuk yang digunakan sebagai metafor yang merujuk referen jari. Di sini, peneliti akan mengetahui bagian tubuh dan sikap perempuan yang mana sajakah yang dimetaforakan dalam masyarakat Madura. Data awal juga dipilah untuk mengetahui jenis nomina apa saja yang digunakan sebagai metafora pengungkap kecantikan fisik atau sikap perempuan dalam masyarakat Madura, misalnya tumbuhan, benda, atau hewan. Kamus kuno Bahasa Madura digunakan untuk membantu peneliti jika ada kata-kata yang tidak dimengerti peneliti dikarenakan kata-kata tersebut tidak lagi dipakai dalam komunikasi oleh masyarakat Madura. Informasi-informasi dari buku-buku yang membahas kebudayaan masyarakat Madura, yang berkaitan dengan praktik-praktik dan nilai kebudayaan serta kehidupan dalam masyarakat Madura yang telah peneliti kumpulkan digunakan untuk mendukung analisis peneliti terkait cara pandang masyarakat Madura yang tercermin dari metafora pengungkap kecantikan perempuan ini. Hal ini bertujuan untuk menghindari subyektifitas peneliti dalam menganalisis dan menginterpretasikan data.

\section{HASIL DAN PEMBAHASAN}

\section{Metafora Pengungkap Kecantikan Fisik Perempuan dalam Masyarakat Madura.}

a. Nangghâl Sakaléan

Kata nangghâl berarti bertanggal, dan kata sakaléan berarti satu kali. Namun, jika disandingkan, frasa nangghâl sakaléan memiliki arti tanggal satu. Arti tanggal satu ini merujuk pada bulan sabit yang biasanya muncul pada awal bulan atau di tanggal pertama pada suatu bulan. Metafora nangghâlsakaléan atau bulan sabit ini digunakan untuk mengungkapkan kecantikan atau keindahan alis perempuan dalam masyarakat Madura. Unsur tenor atau pebanding pada 
metafora ini adalah alis yang indah, dimana alis yang indah ini adalah objek yang dikiaskan. Nangghâl sakélan merupakan vehicle atau pembanding, sementara ground atau persamaan antara tenor dan vehicle ini adalah bentuk bulan sabit dan alis yang melengkung indah.

\section{b. Andâun Membhâ}

Frasa andâun membhâ memiliki arti berdaun mimba. Jika dipilah perkata, kata andâun berarti berdaun, dan kata membhâ berarti mimba. Daun mimba adalah daun tanaman mimba yang banyak tumbuh di daerah kering, seperti Jawa Barat, Jawa Timur, dan Madura. Daun mimba memiliki bentuk lonjong dengan tepi bergerigi, runcing ujungnya, sedikit berambut, sama besar ukuran kedua belah bagiannya, dan melengkung (Backer dkk, 1965). Bentuk daun mimba dijadikan bentuk ideal alis perempuan yang indah, yaitu alis yang melengkung, lonjong dengan ujung runcing, dan agak tebal. Unsur tenor atau pebanding pada metafora ini adalah alis yang indah, dimana alis yang indah ini adalah objek yang dikiaskan. Andâun membhâ merupakan vehicle atau pembanding, sementara ground atau persamaan antara tenor dan vehicle ini adalah bentuk daun mimba dan alis indah yang sama-sama berbentuk lonjong, runcing ujungnya dan melengkung. Melalui metafora andâun membhâ ini, diketahui bahwa kecantikan alis perempuan dalam masyarakat Madura diibaratkan dua hal, yaitu bulan sabit dan daun mimba.

c. Nakér Lémas

Secara harfiah, kata naker berarti mengukur dan kata lémas berarti limas. Frasa nakér lémas diartikan sebagai limas yang terukur. Tidak ada penjelasan khusus terkait limas yang dimaksud, apakah limas tersebut adalah limas segi tiga, limas segi empat, limas segi lima atau limas segi enam. Dari ada satu kesamaan diantara limas-limas tersebut, yaitu bentuk limas-limas tersebut secara umum adalah mengerucut ke atas dan melebar ke bawah. Unsur tenor atau pebanding pada metafora ini adalah pinggul yang indah yang juga menjadi objek yang dikiaskan. Nakér lémas merupakan vehicle atau pembanding, sementara ground atau persamaan antara tenor dan vehicle ini adalah bentuk limas danbentuk pinggul yangmelebar ke bawah. Tidak hanya bentuk pinggul yang lebar, namun juga harus proporsional seperti dalam arti nakér lémas, yaitu limas yang terukur.

d. Bhukor Nongngep

Kata bhukor berarti mangkok logam (Kiliaan, 1905), dan kata nongngep berarti tertelungkup. Jika dua kata tersebut disandingkan, akan terbentuk frasa bhukor nongngep yang berarti mangkok logam yang tertelungkup. Metafora bhukor nongngep atau mangkok logam yang tertelungkup ini digunakan 
untuk mengungkapkan kecantikan atau keindahan pinggul perempuan dalam masyarakat Madura. Unsur tenor atau pebanding pada metafora ini adalah pinggul yang indah yang juga menjadi objek yang dikiaskan. Bhukor nongngep merupakan vehicle atau pembanding, sementara ground atau persamaan antara tenor dan vehicle ini adalah bentuk mangkok logam yang tertelungkup yang melebar ke bawah yang mirip dengan bentuk pinggul yang juga melebar ke bawah. Unsur tenor atau pebanding pada metafora ini adalah sanggul yang indah yang juga menjadi objek yang dikiaskan. Bhukor nongngep merupakan vehicle atau pembanding, sementara ground atau persamaan antara tenor dan vehicle ini adalah bentuk pinggul dan mangkok logam terbalik yang agak mengerucut bentuknya.

Selain itu, metafora bhukor nongngep juga digunakan untuk mengungkapkan keindahan sanggul perempuan Madura, dimana untuk putri bangsawan, dan perempuan dewasa, rambut mereka digelung dengan bentuk seperti mangkok logam yang agak mengerucut bentuknya dan dibalik. Perempuan yang rambutnya digelungbhukor nongngep ini hanya putri keraton dan perempuan dewasa Madura. Bedanya, perempuan dewasa Madura menghiasi gelungnya itu denganbunga cempaka, sementara putri keraton tidak (Wibowo, 2001). Unsur tenor atau pebanding pada metafora ini adalah sanggul yang indah yang juga menjadi objek yang dikiaskan. Bhukor nongngep merupakan vehicle atau pembanding, sementara ground atau persamaan antara tenor dan vehicle ini adalah bentuk sanggul dan mangkok logam terbalik yang agak mengerucut bentuknya.

e. Podhâk Nyongsang

Frasa podhâk nyongsang memiliki arti bunga pandan yang terbalik. Jika dipilah perkata, kata podhâk berarti bunga pandan, dan kata nyongsang berarti terbalik. Bunga pandan memiliki bentuk yang lonjong dengan ujung atas lebih mengerucut dan ujung bawah sedikit melebar. Unsur tenor atau pebanding pada metafora ini adalah betis yang indah yang juga menjadi objek yang dikiaskan. Podhâk nyongsang merupakan vehicle atau pembanding, sementara ground atau persamaan antara tenor dan vehicle ini adalah bentuk betis dan bunga pandan yang terbalik yang mengecil ke bawah. Dalam masyarakat Madura, bentuk betis perempuan yang indah adalah betis yang bentuknya semakin mengecil ke bawah karena perempuan Madura biasanya memakai perhiasan gelang kaki di bawah betis atau pergelangan kakinya.

f. Jhârruk Saloné

Secara harfiah, kata jhârruk berarti jeruk dan kata saloné berarti seiris. 
Frasa jhârruksaloné diartikan sebagai jeruk seiris. Irisan jeruk memiliki bentuk sedikit melengkung dan berisi atau penuh dengan buliran-buliran jeruk. Unsur tenor atau pebanding pada metafora ini adalah bibir yang indah yang juga menjadi objek yang dikiaskan. Jhârruksaloné merupakan vehicle atau pembanding, sementara ground atau persamaan antara tenor dan vehicle ini adalah bentuk bibir perempuan dan seiris jeruk yang tebal atau terlihat penuh.

g. Manggis Ngaréngat

Bibir indah perempuan dalam masyarakat Madura juga diungkapkan dengan metafora lain, yaitu manggis ngaréngat yang berarti manggis yang retak. Seperti yang diketahui bahwa walaupun kulit luar manggis berwarna hitam keunguan dan terkesan gelap, tetapi kulit dalam manggis berwarna merah. Ketika manggis retak maka akan terlihat kulit dalam manggis yang kemerahan dan juga daging buah manggis yang putih. Hal inilah yang membuat bibir perempuan madura diibaratkan dengan manggis yang retak, karena walaupun bibir luarnya berwarna gelap, namun ketika perempuan madura sedikit membuka mulut maka akan terlihat bagian dalam bibir yang kemerahan dan juga gigi yang putih. Unsur tenor atau pebanding pada metafora ini adalah salah satu warna bibir yang indah yang juga menjadi objek yang dikiaskan. Manggis karengat merupakan vehicle atau pembanding, sementara ground atau persamaan antara tenor dan vehicle ini adalah warna bibir perempuan dan warna kulit manggis, yaitu berwarna gelap.

h. Dhâlima Marekka

Tidak hanya bibir gelap indah yang diibaratkan dengan suatu hal oleh masyarakat Madura, bibir merah indah perempuan dalam masyarakat Madura juga diibaratkan dengan suatu hal, yaitu buah delima yang merekah. Kata dhâlima berarti buah delima, sementara kata marekka berarti merekah. Unsur tenor atau pebanding pada metafora ini adalah salah satu warna bibir. Dalima marekka merupakan vehicle atau pembanding, sementara ground atau persamaan antara tenor dan vehicle ini adalah warna bibir perempuan dan warna kulit manggis, yaitu berwarna merah.

\section{i. Bhâu Témbhângan}

Kata bhâu berarti bahu, dan kata témbhânganberarti timbangan. Jika dua kata tersebut disandingkan, akan terbentuk frasa bhâu témbhângan yang berarti bahu timbangan. Metafora bhâu témbhângan atau bahu timbangan ini digunakan untuk mengungkapkan kecantikan atau keindahan bahu perempuan dalam masyarakat Madura. Unsur tenor atau pebanding pada metafora ini adalah salah satu? bahu yang indah yang juga menjadi objek yang dikiaskan. Bhâu témbhângan merupakan vehicle atau pembanding, sementara ground atau 
persamaan antara tenor dan vehicle ini adalah bentuk bahu perempuan dalam masyarakat Madura, yaitu bentuk bahu dan bentuk timbangan yang sama panjang dan tingginya seimbang antara sisi satu dan sisi lainnya.

j. Manjhângan Rampéng

Metafora manjhângan rampéng memiliki arti rusa yang langsing, dimana manjhângan berarti rusa, dan rampéng berarti langsing, indah atau -ramping?. Metafora ini digunakan untuk mengibaratkan tubuh perempuan madura yang langsing, indah, tipis? atau bisa dikatakan mungil. Tubuh rusa yang kecil namun gesit juga mengibaratkan tubuh perempuan dalam masyarakat madura yang walaupun mungil namun tetap gesit dalam melakukan pekerjaan, terutama pekerjaan rumah tangga. Unsur tenor atau pebanding pada metafora ini adalah bentuk tubuh perempuan yang indah yang juga menjadi objek yang dikiaskan. Manjhângan rampéng merupakan vehicle atau pembanding, sementara ground atau persamaan antara tenor dan vehicle ini adalah bentuk tubuh perempuan dan tubuh rusa yang mungil namun gesit dalam melakukan sesuatu.

k. Nyekkar Tanjhung

Kata nyekkar berarti mekar, dan kata tanjhung berarti bunga tanjung. Jika dua kata tersebut disandingkan, akan terbentuk frasa nyekkar tanjhungyang berarti bunga tanjung yang mekar. Metafora nyekkar tanjhung yang berarti bunga tanjung yang mekarini digunakan untuk mengungkapkan kecantikan atau keindahan bulu mata perempuan dalam masyarakat Madura. Unsur tenor atau pebanding pada metafora ini adalah salah bulu mata yang indah yang juga menjadi objek yang dikiaskan. Nyekkar tanjhung merupakan vehicle atau pembanding, sementara ground atau persamaan antara tenor dan vehicle ini adalah bentuk bulu mata perempuan yang lentik dankelopak bunga tanjung yang mekar dan melengkung ke atas.

1. Angapéténg

Metafora angapéténg memiliki arti menyerupai kepiting.. Metafora ini digunakan untuk mengibaratkan dahi perempuan madura yang sedikit lebar, sedikit menonjol dan berkilau. Bagian tubuh kepiting selain capitnya memiliki bentuk yang pipih namunsedikit menonjol dan berkilau. Dahi perempuan dalam masyarakat Madura memiliki bentuk metafora kecantikan karena perempuan madura, terutama putri keraton memiliki kebiasaan menyisir rambutnya ke arah belakang sehingga nampak dahi indah dari perempuan tersebut. Unsur tenor atau pebanding pada metafora ini adalah salah satu bentuk dahi yang indah yang juga menjadi objek yang dikiaskan. Angapéténg merupakan vehicle 
atau pembanding, sementara ground atau persamaan antara tenor dan vehicle ini adalah dahi perempuan dalam masyarakat Maduradan bagian tubuh kepiting selain capitnya yang pipih namun sedikit menonjol dan berkilau.

m. Abhângér Bâjang

Hidung indah perempuan dalam masyarakat Madura diungkapkan dengan metafora abhangnger bâjangyang berarti menghasilkan bayangan. Benda yang memiliki ketinggian tertentu akan menghasilkan bayangan akan dirinya. Unsur tenor atau pebanding pada metafora ini adalah salah satu bentuk hidung yang indah yang juga menjadi objek yang dikiaskan. Abhângér bâjang merupakan vehicle atau pembanding, sementara ground atau persamaan antara tenor dan vehicle ini adalah bentuk hidung dan sesuatu yang menghasilkan bayangan.

n. Ngaleppon Nongko'

Tidak hanya hidung mancung indah yang diibaratkan dengan suatu hal oleh masyarakat Madura, hidung bulat indah perempuan dalam masyarakat Madura juga diibaratkan dengan suatu hal, yaitu kue klepon. Secara harfiah, kata ngaleppon berarti kue klepon (sejenis kue bulat bertekstur lembut dan sedikit kenyal yang biasanya dibuat dari tepung ketan dan dalam nya diisi gula merah lalu luarnya dilumuri parutan kelapa),dan kata nongko' berarti duduk/ terletak di atas sesuatu alas. Frasa ngaleppon nongko'diartikan sebagai kue klepon yang diletakkan di atas. Unsur tenor atau pebanding pada metafora ini adalah hidung yang indah yang juga menjadi objek yang dikiaskan. Ngaleppon nongko 'merupakan vehicle atau pembanding, sementara ground atau persamaan antara tenor dan vehicle ini adalah bentuk dan tesktur hidung dan kue klepon yang bulat namun mungil.

o. Angrajhung Duri

Metafora angrajhung duri memiliki arti ujung duri. Metafora ini digunakan untuk mengibaratkan jari perempuan madura yang lentik dan bentuknya "meruncing" di bagian atasnya (bagian kuku). Tidak ada penjelasan khusus terkait jenis duri tumbuhan apa yang digunakan dalam metafora ini. Namun, ada satu kesamaan diantara bnyak jenis duri secara umum, yaitu mengerucut ke atas dan ujungnya runcing.Unsur tenor atau pebanding pada metafora ini adalah jari yang indah yang juga menjadi objek yang dikiaskan. Angrajhung duri merupakan vehicle atau pembanding, sementara ground atau persamaan antara tenor dan vehicle ini adalah bentuk jari dan ujung duri.

p. Mangkar Ranca'

Gigi indah perempuan dalam masyarakat Madura diungkapkan dengan metafora mangkar ranca' yang berarti menjejerkan ranting. Ranting pohon 
berbentuk sedikit memanjang dan merupakan cabang pohon yang kecil. Unsur tenor atau pebanding pada metafora ini adalah gigi yang cantik yang juga menjadi objek yang dikiaskan. Mangkar ranca'merupakan vehicle atau pembanding, sementara ground atau persamaan antara tenor dan vehicle ini adalah bentuk bulu mata dan bentuk ranting dimana ranting-rating tersebut dijejerkan seperti gigi kecil yang berjejer.

q. Abighi Témon

Gigi indah perempuan dalam masyarakat Madura juga diungkapkan dengan metafora lain, yaitu abighi témonyang berarti berbiji timun. Seperti yang diketahui bahwa biji timun berbentuk oval memanjang dan berwarna putih bersih. Unsur tenor atau pebanding pada metafora ini adalah gigi yang juga menjadi objek yang dikiaskan. Abighi témon merupakan vehicle atau pembanding, sementara ground atau persamaan antara tenor dan vehicle ini adalah bentuk persegi kecil dan warna putih gigi dan biji timun.

r. Molu Kombâng

Metafora lain yang menjadi pengungkap gigi indah perempuan dalam masyarakat Madura metafora molu kombâng. Kata molu berarti berbulu, sementara kombâng berarti kumbang. Bulu kumbang berwarna hitam dan mengkilap dengan bentuk persegi yang lebar. Gigi perempuan dalam masyarakat Madura yang diibaratkan seperti bulu kumbang melalui metafora molu kumbang ini merujuk pada gigi perempuan dewasa dalam masyarakat Madura yang masih mempertahankan budaya meminang sehingga gigi mereka berwarna kuning kehitaman, namun tetap sehat. Unsur tenor atau pebanding pada metafora ini adalah gigi yang juga menjadi objek yang dikiaskan. Molu kombâng merupakan vehicle atau pembanding, sementara ground atau persamaan antara tenor dan vehicle ini adalah bentuk an warna gigi dan bulu kumbang.

s. Angeddhâng Lomot

Masyarakat Madura juga memiliki metafora pengungkap keindahan atau kecantikan kulit perempuan. Metafora tersebut adalah angeddhâng lomot yang berarti pisang lumut atau pisang hijau. Tekstur kulit pisang hijau yang lembut digunakan masyarakat Madura untuk mengibaratkan kulit cantik perempuan Madura yang halus dan lembut. Kulit yang halus dan lembut menunjukkan bahwa perempuan tersebut pandai merawat kesehatan dan kecantikan kulitnya. Unsur tenor atau pebanding pada metafora ini adalah kulit yang juga menjadi objek yang dikiaskan. Angeddhâng lomot merupakan vehicle atau pembanding, sementara ground atau persamaan antara tenor dan vehicle ini adalah tektur kulit perempuan dan kulit pisang hijau. 
t. Anyéor ghâding

Dalam masyarakat Madura, keindahan atau kecantikan kulit perempuan secara umum diungkapkan melalui metafora anyéor ghâding. Arti dari anyéor ghâding itu sendiri adalah kelapa gading. Tidak dijelaskan dengan khusus bagian dari kelapa gading yang manakah yang dijadikan dasar pengibaratan kulit indah perempuan dalam masyarakat Madura. Namun, 3 dari informan yang diwawancarai oleh peneliti mengatakan bahwa pengibaratan kulit indah perempuan sebagai kelapa gading adalah warnanya yang kuning. Unsur tenor atau pebanding pada metafora ini adalah kulit. Anyéor ghâdhing merupakan vehicle atau pembanding, sementara ground atau persamaan antara tenor dan vehicle ini adalah warna kulit perempuan dan kulit kelapa gading.

u. Ngonéng Langsep

Alasan pengibaratan kulit indah atau cantik perempuan dalam masyarakat Madura secara umum juga diungkapkan melalui metafora ngonéng langsep. Kata ngonéng berasal dari kata dasar konéng yang berarti kuning, sementara kata langsep berarti buah langsat atau buah duku. Walaupun metafora ini digunakan untuk mengungkapkan keindahan kulit perempuan secara umum, tetapi jelas terlihat dari makna metafora ngonep langsep atau kuning buah langsat bahwa kulit cantik perempuan Madura adalah yang berwarna kuning seperti kuningnya buah langsat atau buah duku. Unsur tenor atau pebanding pada metafora ini adalah kulit. Ngonéng langsep merupakan vehicle atau pembanding, sementara ground atau persamaan antara tenor dan vehicle ini adalah warna kulit perempuan dan kulit buah langsep.

v. Emmas Ésangléng

Metafora emmas ésangléng digunakan untuk kulit yang lebih spesifik warnanya yaitu kulit kuning. Kata emmas berarti emas, sementara kata ésangléng berarti digosok. Jadi, warna kuning di sini merujuk pada warna kuning emas. Tidak hanya warna kuningnya, tetapi juga kilauan emas yang terpancar ketika emas tersebut digosok. Kulit yang berwarna kuning seperti emas juga harus berkilau ibarat emas yang digosok. Kulit yang berkilau menunjukkan bahwa kulit tersebut tidak kering dan sehat. Unsur tenor atau pebanding pada metafora ini adalah kulit kuning. Emmas ésangléngmerupakan vehicle atau pembanding, sementara ground atau persamaan antara tenor dan vehicle ini adalah warna dan sifat kulit perempuan dan emas yang digosok.

\section{w. Konéng Mondhu}

Kulit kuning perempuan dalam masyarakat Madura juga diungkapkan dengan metafora lain, yaitu konéng mondhu yang berarti kuning buah mundu. 
Buah mundu adalah buah yang baik kulit maupun daging buahnya berwarna kuning terang. Unsur tenor atau pebanding pada metafora ini adalah kulit kuning. Konéng mondhu merupakan vehicle atau pembanding, sementara ground atau persamaan antara tenor dan vehicle ini adalah warna kulit perempuan, dan kulit dan daging buah mundu.

x. Celleng Mangghis

Masyarakat Madura juga menganggap kulit gelap sebagai kulit yang cantik. Pengungkapan keindahan atau kecantikan kulit gelap perempuan dalam masyarakat Madura adalah melalui metafora celleng mangghis. Kata celleng berarti hitam, dan kata mangghis berarti manggis. Jadi, frasa untuk metafora celleng mangghis berarti hitam manggis. Unsur tenor atau pebanding pada metafora ini adalah kulit gelap. Celleng mangghis merupakan vehicle atau pembanding, sementara ground atau persamaan antara tenor dan vehicle ini adalah warna kulit perempuan dan kulit manggis.

y. Ngalong Tontonan

Bentuk leher indah perempuan dalam masyarakat Madura diibaratkan dengan berkalung ari-ari bayi yang diungkapkan melalui metafora ngalong tontonan. Kata ngalong berarti berkalung, sementara tontonan berarti ariari bayi. Ibu yang mengandung bayi yang terlilit ari-arinya akan melalui proses melahirkan yang susah. Hal ini juga mengakibatkan adanya garisgaris horisontal pada leher bayi yang akan terus ada hingga dirinya dewasa. Garis-garis pada leher perempuan ini, menurut masyarakat Madura, adalah ciri leher yang cantik dan indah untuk perempuan. Unsur tenor atau pebanding pada metafora ini adalah leher. Ngalong tontonan merupakan vehicle atau pembanding, sementara ground atau persamaan antara tenor dan vehicle ini adalah bentuk leher dan ari-ari bayi.

z. Angghulu Manjhângan

Terkait bentuk leher indah perempuan, masyarakat Madura memiliki metafora lain untuk mengungangkapkannya, yaitu metafora angghulu manjhângan. Kata angghulu berarti leher, sementara kata manjhângan berarti rusa. Leher perempuan yang jenjang dikategorikan sebagai leher yang indah dan diibaratkan leher rusa yang juga jenjang (panjang dan langsing). Unsur tenor atau pebanding pada metafora ini adalah leher. Angghulu manjhângan merupakan vehicle atau pembanding, sementara ground atau persamaan antara tenor dan vehicle ini adalah bentuk leher perempuan dan leher rusa.

aa. Bintang Kartéka

Metafora bintang kartéka digunakan oleh masyarakat Madura untuk 
mengungkapkan keindahan atau kecantikan mata perempuan. Menurut kepercayaan orang Madura, bintang kartéka adalah bintang yang memberi petunjuk kepada nelayan tentang arah angin dan musim ikan (Moelyono dkk, 1983/ 1984: 70). Nelayan biasanya melaut di malam hari, dan cahaya dari bintang kartéka ini mampe membantu mereka untuk menentukan arah angin, dan juga menjadi tanda musim ikan. Hal ini menunjukkan bahwa bagian dari bintang kartéka yang dijadikan pengibaratan mata indah perempuan dalam masyarakat Madura bukanlah bentuknya tetapi cahayanya. Jadi, mata indah perempuan dalam masyarakat Madura adalah mata yang bercahaya dan terkesan hidup. Unsur tenor atau pebanding pada metafora ini adalah mata. Bintang kartékamerupakan vehicle atau pembanding, sementara ground atau persamaan antara tenor dan vehicle ini adalah sifat mata dan bintang kartéka yang berkilau. ab. Ambulan Pornama

Wajah indah perempuan dalam masyarakat Madura diungkapkan dengan metafora lain, yaitu ambulan pornama yang berarti bulan purnama, dimana ambulan berarti bulan, dan pornama berarti purnama.Seperti yang diketahui bahwa bulan purnama berbentuk bulat penuh. Kemunculan bulan purnama, yang tidak setiap malam, membuat orang terkesima dan mengagumi keindahannya. Unsur tenor atau pebanding pada metafora ini adalah wajah. Ambulan pornamamerupakan vehicle atau pembanding, sementara ground atau persamaan antara tenor dan vehicle ini adalah bentuk dan sifat wajah dan bulan purnama.

ac. Malé' Katopa'

Metafora malé katopa' digunakan masyarakat Madura untuk mengungkapkan keindahan atau kecantikan rambut ikal atau keriting perempuan. Kata malé 'berarti membalik, sementara kata katopa' berarti ketupat. Namun, jika dua kata ini disandingkan, maka maknanya adalah ketupat yang terbalikbalik. Rambut ikal yang terkesan "terbalik-balik" atau "melengkung-lengkung" diibaratkan beberapa ketupat yang digantung dengan ujung tiap ketupat (janurnya) yang melengkung. Penggunaan ketupat tidak lepas dari hari raya idul fitri, dimana islam merupakan agama mayoritas yang dianut masyarakat Madura. Unsur tenor atau pebanding pada metafora ini adalah rambut keriting. Malé' katopa'merupakan vehicle atau pembanding, sementara ground atau persamaan antara tenor dan vehicle ini adalah bentuk rambut ikal dan ketupat.

\section{ad. Andân-andân}

Metafora lain yang juga mengungkapkan keindahan rambut perempuan Madura adalah metafora andân-andân. Bentuk rambut yang keindahannya 
diungkapkan melalui metafora ini adalah bentuk rambut yang panjang. Kata andân-andânini sendiri bermakna bergelombang seperti anak tangga yang berundak-undak. Bisa dikatakan, rambut indah perempuan dalam masyarakat Madura bukanlah rambut yang lurus sempurna tetapi rambut yang bergelombang, ikal dan atau panjang, yang salah satunya diungkapkan dalam metafora malé' katopa'sebelumnya. Unsur tenor atau pebanding pada metafora ini adalah rambut panjang. Andân-andânmerupakan vehicle atau pembanding, sementara ground atau persamaan antara tenor dan vehicle ini adalah bentuk rambut panjang dan anak tangga.

ae. NyambhâlBijjhân

Masyarakat Madura juga memiliki metafora pengungkap kecantikan atau keindahan rambut yang beruban. Metafora yang digunakan adalah metafora nyambhâlbijjhân yang secara harfiah berarti sambal wijen. Uban yang berwarna putih diantara rambut hitam diibaratkan wijen putih dalam sambal yang warnanya coklat pekat atau coklat kehitaman (sambal khas Madura dengan petis ikan tuna Madura). Unsur tenor atau pebanding pada metafora ini adalah uban. Nyambhâlbijjhânmerupakan vehicle atau pembanding, sementara ground atau persamaan antara tenor dan vehicle ini adalah warna uban dan wijen.

\section{af. Andhurin Salénéng}

Ada dua metafora yang digunakan masyarakat Madura untuk mengungkapkan kecantikan atau keindahan pipi perempuan dalam masyarakat Madura. Metafora yang pertama adalah andhurin salénéng. Kata andhurin berarti durian, sementara kata salénéng berarti sebiji. Bentuk satu biji durian yang hampir bulat penuh karena bijinya yang bulat, padat, namun tetap lembut dijadikan dasar pengibaratan pipi yang indah dan cantik perempuan dalam masyarakat Madura. Pipi yang indah dan cantik adalah pipi yang tidak tirus, tetapi pipi yang indah dan cantik adalah pipi yang berisi, agak tembam dan lembut. Unsur tenor atau pebanding pada metafora ini adalah pipi. Andhurin salénéngmerupakan vehicle atau pembanding, sementara ground atau persamaan antara tenor dan vehicle ini adalah bentuk dan tekstur pipi dan sebiji durian.

ag. Ngalompang

Metafora pengungkap kecantikan atau keindahan pipi perempuan yang kedua dalam masyarakat Madura adalah ngalompang. Kata ngalompang berasal dari kata dasar lompang yang berarti kue lumpang. Kue lumpang adalah kue berbahan dasar tepung beras, tepung ketan, dan santan. Bentuk kue lumpang seperti cangkir yang sangat kecil dan memiliki cekungan kecil ditengah atasnya. Tekstur dari kue lumpang ini adalah lembut dan kenyal. Pipi yang dibaratkan 
dengan bentuk, dan tekstur kue lumpang ini adalah pipi yang lembut, berisi dan memiliki lesung pipi seperti cekungan kecil di tengah kue lumpang. Unsur tenor atau pebanding pada metafora ini adalah pipi. Ngalompang merupakan vehicle atau pembanding, sementara ground atau persamaan antara tenor dan vehicle ini adalah bentuk dan tekstur pipi dan kue lumpang.

ah. Abhâru Loros

Metafora abhâru loros digunakan untuk mengungkapkan kecantikan atau keindahan paha perempuan dalam masyarakat Madura. Frasa abhâru loros berarti pohon waru yang lurus. Pohon waru adalah jenis pohon yang memiliki batang tinggi dan kecil. Pohon Waru biasanya tumbuh subur di tanah yang tidka gersang, namun tetap bisa bertahan di kondisi tanah gersang. Bentuk pohon waru ini dijadikan dasar pengibaratan paha yang cantik daa indah perempuan dalam masyarakat Madura, yaitu paha yang jenjang dan kecil. Unsur tenor atau pebanding pada metafora ini adalah paha. Abhâru loros merupakan vehicle atau pembanding, sementara ground atau persamaan antara tenor dan vehicle ini adalah bentuk paha dan pohon waru yang lurus.

ai. Mokang Jhârring

Masyarakat Madurajuga mempunyai metafora lain untuk mengungkapkan keindahan dan kecantikan paha perempuan. Metafora tersebut adalah mokang jhârring yang berarti paha jangkrik. Paha yang indah diibaratkan dengan paha jangkrik yang bentuknya lebar di bagian pangkal dan kecil di ujung paha (di atas lutut). Jadi, dari metafora ini, diketahui bahwa masyarakat Madura juga memandang paha perempuan yang tidak kecil sebagai paha yang juga indah dan tetap dianggap cantik.

aj. Nyéngkér Ghâdhing

Metafora nyéngkér ghâding digunakan untuk mengungkapkan kecantikan atau keindahan payudara perempuan dalam masyarakat Madura. Frasa nyéngkér ghâding terdiri dari kata nyéngkér yang berarti kelapa muda, dan gadhing yang berarti gading (jenis kelapa). Jadi, metafora nyéngkér ghâding berarti kelapa gading muda. Kelapa gading memiliki bentuk bulat dan lonjong dibagian depan. Hageman dalam de Jonge (2011: 65) menyatakan bahwa satu-satunya hal positif dari fisik perempuan Madura, dari banyaknya stereotip negatif orang Madura, adalah payudaranya yang bagus dimana hal ini disebabkan oleh kebiasaan perempuan Madura yang tidak memakai kemben seperti perempuan Jawa dan Sunda, dan kebiasaan perempuan Madura yang terbiasa membawa sesuatu di kepala. Kebiasaan membawa barang di kepala ini membantu dada mereka terbusung dan tubuh mereka tegap. Unsur tenor atau pebanding pada metafora 
ini adalah payudara. Nyéngkér ghâdhing merupakan vehicle atau pembanding, sementara ground atau persamaan antara tenor dan vehicle ini adalah bentuk payudara dan kelapa gading muda.

ak. Ngokot Manjhângan

Untuk kaki indah, masyarakat Madura menggunakan metafora ngokot manjhângan. Kata ngokot berarti kaki (untuk binatang), sementara manjhângan berarti rusa. Walaupun kaki rusa kecil, namun kaki rusa kuat digunakan untuk berlari di hutan, terutama untuk menghindari pemburu dan ancaman hewan yang akan memangsanya. Kaki indah perempuan, oleh masyarakat Madura, diibaratkan dengan kaki yang kecil dan tetap kuat untuk menopang tubuh dalam melakukan berbagai macam aktivitas, terutama pekerjaan rumah tangga. Unsur tenor atau pebanding pada metafora ini adalah kaki. Ngokot manjhânganmerupakan vehicle atau pembanding, sementara ground atau persamaan antara tenor dan vehicle ini adalah bentuk kaki perempuan dan kaki rusa.

al. Nellor Mano'

Metafora pengungkap kecantikan atau keindahan fisik perempuan dalam masyarakat Madura yang terakhir adalah metafora nellor mano'. Metafora nellor mano' digunakan oleh masyarakat Madura untuk mengungkapkan keindahan atau kecantikan tumit perempuan. Metafora nellor mano' berarti telur burung. Unsur tenor atau pebanding pada metafora ini adalah tumit. Nellor mano' merupakan vehicle atau pembanding, sementara ground atau persamaan antara tenor dan vehicle ini adalah bentukdan tekstur tumit dan telur burung yang bulat oval dan halus.

\section{Metafora Pengungkap Kecantikan Perilaku Perempuan dalam Masyarakat Madura.}

a. Paé'Maddhu

Metafora paé' maddhu digunakan untuk mengungkapkan kecantikan atau keindahan cara berbicara perempuan dalam masyarakat Madura. Frasa paé' maddhu berarti pahit madu. Kedua hal yang disandingkan ini adalah dua hal yang bertolak belakang. Madu memiliki rasa manis yang bertolak belakang dengan rasa pahit. Mcara berbicara yang indah yang dilakukan oleh perempuan, menurut masyarakat Madura, harus tegas dan jujur namun tetap dengan cara yang lembut dan sopan. Unsur tenor atau pebanding pada metafora ini adalah cara berbicara. Paé' maddhumerupakan vehicle atau pembanding, sementara ground atau persamaan antara tenor dan vehicle ini adalah sifat dan rasa cara berbicara dan pahit madu. Kemudian, berdasarkan semiotikanya, dapat dilihat bahwa paé' maddhu merupakan tanda, madu merupakan penanda, dan cara bicara yang 
indah merupakan sesuatu yang ditandai. Metafora pengungkap kecantikan sifat perempuan dalam masyarakat Madura tidak disertai gambar karena metofora yang digunakan lebih kepada gerakan yang sulit digambarkan dalam gambar dua dimensi.

\section{b. Meltas Manjhâlin}

Masyarakat Madura menggunakan metafora meltas manjhâlinuntuk mengungkapkan cara melambai yang indah yang dilakukan oleh perempuan. Kata meltas memiliki arti melenting, sementara kata manjhâlin memiliki arti Metafora meltas manjhâlin memiliki arti rotan. Jadi, metafora meltas manjhâlin memiliki arti rotan yang melenting. Cara melambai yang indah dalam masyarakat Madura adalah cara melambai yang lentur, lembut dan anggun seperti rotan yang memiliki struktur batang yang lentur sehingga mudah dibentuk menjadi banyak barang kerajinan. Unsur tenor atau pebanding pada metafora ini adalah cara melambai. Meltas manjhâlin merupakan vehicle atau pembanding, sementara ground atau persamaan antara tenor dan vehicle ini adalah sifat cara melambai dan kayu rotan. Kemudian, berdasarkan semiotikanya, dapat dilihat bahwa meltas manjhâlin merupakan tanda, kayu rotan merupakan penanda, dan cara melambai yang indah merupakan sesuatu yang ditandai.

c. Nétér Kolénang

Terkait cara berjalan yang indah oleh perempuan, masyarakat Madura juga memiliki metafora untuk mengungkapkannya. Metafora tersebut adalah nétér kolénang. Kata nétér berarti mengikuti dengan pelan dan sedikit berjinjit, sementara kata kolénang berartialatmusikbonang. Alatmusikbonang merupakan salah satu alat musik yang digunakan dalam pertunjukan musik tradisional khas Madura, yang disebut saronén. Alunan musik saronén yang cepat biasanya digunakan pada pacuan kerapan sapi, sementara alunan musik yang pelan dan lembut digunakan untuk mengiringi orang berjalan menuju pemakaman, pengantin naik kuda, perhelatan, dan masuknya pengantin ke pelaminan, dimana langkah kaki menjadi teratur, pelan, dan seirama dengan alunan bonang dari musik saronén ini (Karim, 2004: 45). Langkah kaki yang teratur dan seirama dengan alunan musik dari saronéni nilah yang dijadikan dasar pengibaratan cara berjalan yang indah perempuan dalam masyarakat Madura. Cara berjalannya harus teratur dan pelan. Unsur tenor atau pebanding pada metafora ini adalah cara berjalan. Nétér kolénang merupakan vehicle atau pembanding, sementara ground atau persamaan antara tenor dan vehicle ini adalah sifat cara berjalan dan alunan musik bonang. Kemudian, berdasarkan semiotikanya, dapat dilihat bahwa nétér kolénang merupakan tanda, alunan musik bonang merupakan 
penanda, dan cara berjalan yang indah merupakan sesuatu yang ditandai.

d. DhâmarKaangénan

Metafora dhâmarkaangénan digunakan oleh masyarakat Madura untuk mengungkapkan keindahan cara melihat perempuan terhadap seseorang atau sesuatu. Kata dhâmarberarti lampu, sementara kata kaangénan berarti terkena angin. Frasa dhâmar kaangean berarti lampu yang terkena angin. Lampu di sini merujuk pada lampu teplok yang memiliki sumbu untuk disulut api dan berbahan bakar minyak tanah. Cara melihat yang tajam namun sedikit sayu dan bercahaya diibaratkan dengan lampu teplok yang sumbunya telah disulut api dan terkena angin. Unsur tenor atau pebanding pada metafora ini adalah cara melihat. Dhâmarkaangénanmerupakan vehicle atau pembanding, sementara ground atau persamaan antara tenor dan vehicle ini adalah sifat cara melihat dan api dalam lampu teplok yang tertiup angin. Kemudian, berdasarkan semiotikanya, dapat dilihat bahwa dhâmar kaangénan merupakan tanda, api lampu teplok merupakan penanda, dan cara melihat yang indah merupakan sesuatu yang ditandai.

e. Mésem Bâlibis

Metafora mésembâlibis berarti senyum burung belibis. Burung belibis sering juga disebut bebek bersiul karena hewan ini selalu mengeluarkan suara merdu seperti siulan burung. Mulut burung belibis sedikit lebar dan mirip dengan mulut bebek. Metafora ini digunakan oleh masyarakat Madura untuk mengungkapkan keindahan cara tertawa seorang perempuan. Cara tertawa yang indah, merdu, namun tidak sampai memperlihatkan banyak gigi, dan terlihat seperti senyuman lebar diibaratkan dengan senyum burung belibis. Unsur tenor atau pebanding pada metafora ini adalah cara tertawa. Mésem belibis merupakan vehicle atau pembanding, sementara ground atau persamaan antara tenor dan vehicle ini adalah sifat cara tertawa dan burung belibis. Kemudian, berdasarkan semiotikanya, dapat dilihat bahwa mésembâlibis merupakan tanda, senyum burung belibis merupakan penanda, dan cara tertawa yang indah merupakan sesuatu yang ditandai.

\section{f. Lemma'Manis}

Metafora pengungkap keindahan difat perempuan dalam masyarakat Madura yang terakhir adalah metafora lemaq manis. Metafora ini digunakan untuk mengungkapkan keindahan suara perempuan dalam masyarakat Madura. Kata lemaq berarti lemak, dan kata manis berarti manis. Istilah lemak manis mengacu pada rasa makanan atau jajanan yang biasanya dihidangkan pada acaraacara tertentu, seperti pernikahan. Unsur tenor atau pebanding pada metafora ini adalah suara. Lemma' manes merupakan vehicle atau pembanding, sementara 
ground atau persamaan antara tenor dan vehicle ini adalah sifat cara tertawa dan sesuatu yang lemak manis. Kemudian, berdasarkan semiotikanya, dapat dilihat bahwa lemma' manis merupakan tanda, rasa lemak manis merupakan penanda, dan suara yang indah merupakan sesuatu yang ditandai.

\section{g. Ngamantan Anyar}

Kecantikan, keindahan, dan keanggunan cara perempuan diam dalam masyarakat Madura juga diungkapkan melalui metafora tertentu, yaitu metafora ngamantan anyar. Kata ngamantan berarti pengantin dan kata anyar berarti baru. Jadi, arti ngamantan anyar adalah pengantin baru. Cara diam perempuan yang tenang, tersenyum, sopan, dan sedikit pemalu diibaratkan cara diamnya pengantin baru yang juga saling merasa malu, dan tersenyum. Unsur tenor atau pebanding pada metafora ini adalah cara diam. Ngamantan anyar merupakan vehicle atau pembanding, sementara ground atau persamaan antara tenor dan vehicle ini adalah sifat cara berjalan dan pengantin baru. Kemudian, berdasarkan semiotikanya, dapat dilihat bahwa ngamantan anyar merupakan tanda, pengantin baru merupakan penanda, dan cara diam yang indah merupakan sesuatu yang ditandai.

h. Nyaghâra

Metafora nyaghâra memiliki arti melaut/ seperti laut. Kata nyaghâra berasal dari kata dasar saghara yang berarti laut. Metafora ini digunakan oleh masyarakat Madura untuk mengungkapkan keindahan cara berpikir perempuan. Pemikiran yang luas diibaratkan dengan laut yang juga luas. Unsur tenor atau pebanding pada metafora ini adalah cara berpikir. Nyaghâra merupakan vehicle atau pembanding, sementara ground atau persamaan antara tenor dan vehicle ini adalah sifat dan bentuk cara berpikir dan laut. Kemudian, berdasarkan semiotikanya, dapat dilihat bahwa nyaghâra merupakan tanda, lautan merupakan penanda, dan cara berpikir yang indah merupakan sesuatu yang ditandai.

i. Bhânténg Akérék

Terkait cara melirik yang indah oleh perempuan, masyarakat Madura juga memiliki metafora untuk mengungkapkannya. Metafora tersebut adalah bhânténg akérék. Kata bhânténg berarti banteng (binatang), sementara kata akérék berarti mengeluarkan suara ketika sedang marah. Jika diibaratkan harimau, maka akérék mengacu pada mengaum. Lirikan yang tajam dan fokus kepada satu objek dianggap indah dalam masyarakat Madura dan diibaratkan seperti cara melirik banteng yang sedang marah. Unsur tenor atau pebanding pada metafora ini adalah cara melirik. Bhânténg akérék merupakan vehicle atau pembanding, sementara ground atau persamaan antara tenor dan vehicle 
ini adalah sifat dan tampilan cara melirik dan banteng yang marah. Kemudian, berdasarkan semiotikanya, dapat dilihat bahwa bhânténg akérék merupakan tanda, banteng merupakan penanda, dan cara melirik yang indah merupakan sesuatu yang ditandai.

j. Nyaop Séka'

Sifat ringan tangan perempuan dalam masyarakat Madura juga diungkapkan dengan metafora tertentu, yaitu metafora nyaop séka'. Kata nyaop dalam Bahasa Madura kuno berarti menyambar (Kiliaan, 1904: 379), dan kata séka 'berarti layang-layang (Kiliaan, 1904: 402). Sifat ringan tangan perempuan dalam masyarakat Madura diibaratkan orang, biasanya anak kecil ketika mengejar layang-layang dan berusaha mengambilnya. Dalam aktivitas itu, mereka sangat antusias, bahagia, semangat dan tidak berhenti sebelum layang-layang yang menjadi target mereka didapat. Jadi, sifat ringan tangan yang disematkan pada diri perempuan cantik dalam masyarakat Madura adalah sifat ringan tangan yang ikhlas, antusias dan tidak terbatas dalam memberi pertolongan. Unsur tenor atau pebanding pada metafora ini adalah sifat ringan tangan. Nyaop séka'merupakan vehicle atau pembanding, sementara ground atau persamaan antara tenor dan vehicle ini adalah sifat antusias dan semangat ringan tangan dan mengambil layang-layang. Kemudian, berdasarkan semiotikanya, dapat dilihat bahwa nyaop séka'merupakan tanda, layang-layang merupakan penanda, dan sifat ringan tangan yang indah merupakan sesuatu yang ditandai.

\section{Cara Pandang Masyarakat Madura yang Tercermin dari Metafora Pengungkap}

\section{Kecantikan Perempuan.}

Berdasarkan deskripsi metafora-metafora pengungkap kecantikan perempuan dalam masyarakat Madura pada sub-bab sebelumnya, dapat diketahui bahwa metafora-metafora tersebut lebih banyak berupa metafora pengungkap kecantikan fisik perempuan. Dari total 49 metafora pengungkap kecantikan perempuan, 39 diantaranya merupakan metafora pengungkap kecantikan fisik perempuan. Sementara itu, 10 diantaranya merupakan metafora pengungkap kecantikan sikap perempuan dalam masyarakat Madura. Melalui hasil deskripsi metafora tersebut, ada beberapa cara pandang masyarakat Madura yang tercermin di dalamnya. Yang pertama, masyarakat Madura lebih memandang kecantikan perempuan secara fisik sebagai kecantikan yang lebih dominan untuk diungkapkan dengan metafora-metafora tersebut. Hal ini dibuktikan dengan masih terjaganya tradisi minum jamu oleh masyarakat Madura, terutama di daerah pedesaan. Perempuan Madura mempertahankan tradisi minum jamu ini dengan tujuan tidak hanya untuk kesehatan tetapi juga untuk kecantikan fisik, seperti membuat badan langsing atau menjaga badan manjhângan rampéng mereka. 
Tidak hanya itu, tradisi menggunakan lulur masih sangat kuat dipertahankan oleh masyarakat Madura, terutama perempuan Sumenep, agar kulitnya ngonéng langsep, angeddhâng lomot, anyéor ghâdhing, konéng mondu, celleng mangghis atau emmas ésangléng. Lebih besarnya jumlah metafora pengungkap kecantikan fisik perempuan dalam masyarakat Madura juga dipengaruhi faktor lebih mudahnya kecantikan fisik dimetaforakan walaupun hanya melalui gambar, sementara kecantikan sikap tidak bisa dimetaforakan jika tidak melihat kecantikan sifat tersebut secara langsung.

Kemudian, masyarakat Madura juga lebih banyak memiliki metafora pengungkap kecantikan fisik untuk bagian wajah dan kepala, seperti rambut, dahi, alis, mata, hidung, pipi, bibir, dan gigi. Ini menunjukkan bahwa bagian wajah dan kepala merupakan pusat kecantikan perempuan dan bagian tubuh yang penting dalam kaitannya dengan konsep kecantikan dalam masyarakat Madura. Namun, dari bagian wajah dan kepala, ada beberapa bagian yang tidak diungkapkan kecantikan atau keindahannya melalui metafora, yaitu telinga, dan dagu. Kemungkinan yang terjadi adalah masyarakat Madura memandang dua bagian wajah dan kepala ini sebagai bagian yang umum dan tidak perlu diungkapkan sebagai suatu bagian yang indah atau cantik. Atau, masyarakat Madura tidak memiliki pengalaman yang berkaitan dengan hal lain dalam hidupnya yang bisa dijadikan perbandingan dengan keindahan sifat, bentuk dan lainnya denga telinga dan dagu. Telah dinyatakan sebelumnya bahwa, menurut Lakoff dan Jhonson (dalam Duranti, 2007: 65), metafora adalah wadah bagi hubungan antara manusia dan pengalaman dalam hidupnya.

Hal yang sama juga berlaku untuk bagian tubuh yang lain, misalnya saja, masyarakat Madura tidak memiliki metafora pengungkap kecantikan untuk siku, lengan atas, lengan bawah, telapak tangan, lutut, dan bagian lain yang tidak ada dalam deskripsi metafora-metafora pengungkap kecantikan perempuan dalam masyarakat Madura sebelumnya. Sementara itu, untuk konsep kecantikan sifat perempuan, walaupun hanya ada 10 metafora, namun kesemuanya mampu mewakili sifat-sifat dasar yang dituntut masyarakat Madura untuk hadir dalam diri setiap perempuan. Misalnya saja, cara melihat, melirik, berbicara, tertawa, melambai, berjalan, berpikir, bersuara, diam, dan menolong orang (ringan tangan). Ini menunjukkan bahwa masyarakat Madura memandang sikap-sikap perempuan sangat penting dalam interaksi sosial. Budi pekerti, kesopanan, keramahan, dan keanggunan merupakan sikap-sikap yang harus dimiliki oleh perempuan dari sudut pandang masyarakat Madura. Hal ini berkaitan juga dengan panutan umum tentang konsep perempuan cantik dalam masyarakat Madura, yaitu Raden Ayu Potré Konéng yang tidak hanya cantik paras dan fisiknya, tetapi juga sifatnya sehingga sangat dipuja dan disegani.

Cara pandang lain yang dimiliki oleh masyarakat Madura yang tercermin dari 
metafora pengungkap kecantikan perempuan adalah tidak semua konsep kecantikan berpatokan pada satu bentuk atau warna ideal suatu bagian tubuh tertentu. Semua perbedaan warna dan bentuk fisik bagian tubuh tertentu tetap dikagumi, diapresiasi dan dianggap cantik oleh masyarakat Madura. Misalnya saja, rambut yang cantik atau indah perempuan dalam masyarakat Madura ada tiga bentuk, yaitu rambut ikal malé' katopa', rambut panjang andân-andân dan rambut beruban nyambhâl bijjhân; alis yang cantik ada dua bentuk yaitu alis melengkung sempurna nangghâlsakaléandan alis tebal dan runcing andânmembhâ; leher yang cantik ada dua, yaitu leher bergarisgaris ngalong tontonan dan leher jenjang angghulu manjangan; gigi yang cantik adatiga, yaitu gigi kecil putih ambighi témon, gigi hitam molu kombângdan gigi rapat mangkar ranca'; bibir yang cantik ada tiga, yaitu bibir tebal jhârruk saloné, bibir gelap mangghis karengat, dan bibir merah delima marekka; pipi yang cantik ada dua, yaitu pipi tembam andhurin salénéng dan pipi berlesung pipit ngalompang; paha yang cantik ada dua , yaitu paha berisi mokang jhârring dan paha kecil abhâru loros; dan yang cantik ada lima, yaitu kulit kuning konéng mondhu, kulit gelap celleng mangghis, kulit halus angeddhâng lomot, kulit bercahaya anyéor ghâdhing dan ngonéng langsep.

Selanjutnya, 49 metafora pengungkap kecantikan, baik fisik maupun sikap, dalam masyarakat Madura, meliputi sumber pembanding yang berbeda, terutama jenisnya. Jenis pembanding yang menggunakan nama-nama tumbuhan merupakan jenis pembanding yang banyak digunakan oleh masyarakat Madura. Nama-nama tumbuhan ini meliputi nama bunga, daun, buah, dan pohon. Sementara itu, jenis pembanding yang menggunakan nama hal yang lebih erat kaitannya dengan manusia, misalnya ari-ari bayi dan pengantin baru, yang masing-masing berjumlah satu. Jenis pembanding lain muncul dengan jumlah yang berbeda-beda, seperti yang terlihat pada tabel berikut ini:

Tabel 1: Jenis dan Jumlah Pembanding dalam Metafora Pengungkap Kecantikan Perempuan dalam Masyarakat Madura

\begin{tabular}{|c|c|c|}
\hline No. & Jenis Pembanding & Jumlah \\
\hline 1. & Tumbuhan & 17 \\
\hline 2. & Peralatan & 10 \\
\hline 3. & Binatang & 9 \\
\hline 4. & Makanan & 6 \\
\hline 5. & Alam & 5 \\
\hline 6. & Lain-lain & 2 \\
\hline \multicolumn{2}{|c|}{ Total } & $\mathbf{4 9}$ \\
\hline
\end{tabular}

Jenis dan jumlah pembanding dalam metafora pengungkap kecantikan perempuan dalam masyarakat Madura di atas menunjukkan bahwa masyarakat Madura memandang kecantikan lebih kepada perbandingan keindahan tumbuhan yang ada ada disekitar 
mereka. Tentu saja, tumbuhan yang ada di sekitar kehidupan masyarakat Madura adalah tumbuhan yang tumbuh dengan baik di Pulau Madura yang kondisi tanahnya berkapur, gersang, tandus, dan kurang subur. Contohnya adalah pohon mimba dan pohon buah mundu. Penggunaan pembanding pohon mimba, dan pohon buah mundu, misalnya, menunjukkan bahwa ada sebuah pengalaman yang dialami masyarakat Madura yang ada kaitannya dengan dua pohon ini sehingga kemudian masyarakat Madura menggunakannya sebagai bentuk metafora pengungkap kecantikan perempuan. Keesing dalam Duranti (1997: 38) menjelaskan bahwa penggunaan metafora juga mencerminkan budaya masyarakat tersebut. Dalam hal ini, penggunaan tumbuhan yang paling banyak sebagai bentuk metafora menunjukkan adanya budaya masyarakat Madura yang berkaitan dengan tumbuhan, misalnya budaya atau tradisi meminum jamu untuk merawat kesehatan dan keindahan tubuh. Jamu-jamu yang dikonsumsi oleh masyarakat ini diolah dari berbagai macam jenis tumbuhan. Tidak hanya untuk kesehatan dan perawatan tubuh, tumbuhan juga digunakan oleh masyarakat Madura untuk mengatur jarak kelahiran, dan menolak bala atau pengaruh sihir (Moelyono dkk, 1983/ 1984: 70). Hal ini sesuai dengan apa yang disampaikan oleh Boas (dalam Ahearn, 2012: 66) yang menyatakan bahwa suatu bahasa tertentu, dalam hal ini metafora, yang digunakan oleh suatu masyarakat cenderung mencerminkan praktik-praktik budaya masyarakat itu sendiri.

Tidak hanya tumbuhan, cara pandang masyarakat Madura juga tercermin dari pemakaian nama-nama lain yang digunakan untuk pembanding metafora pengungkap kecantikan perempuan. Contohnya, metafora cara berjalan yang indah untuk perempuan adalah nétér kolénang yang berarti alunan musik bonang. Dari metafora ini tercermin budaya atau prakitik-praktik seni musik saronén dalam masyarakat Madura yang salah satu alat musiknya adalah bonang. salah satu jenis binatang yang digunakan oleh masyarakat Madura sebagai pengungkap kecantikan perempuan adalah rusa. Bahkan, rusa muncul dalam tiga bentuk metafora, yaitu angghulu manjhângan untuk leher, manjhângan rampéng untuk tubuh, dan ngokot manjhângan untuk kaki. Hal ini tidak lepas dari budaya atau tradisi berburu masyarakat Madura jaman dahulu, dimana rusa adalah salah satu sasaran buruan utama di hutan, terutama hutan-hutan di Pulau Kangean, Sumenep (Moelyono dkk, 1983/ 1984: 76). Yang lainnya adalah namanama fenomena alam, misalnya bulan purnama pada metafora ambulan pornama danbintang kartika pada metafora bintang kartéka. Dijelaskan sebelumnya bahwa dalam kepercayaan masyarakat Madura, bintang kartika adalah bintang yang mampu memberikan petunjuk kepada nelayan tentang musim ikan dan arah angin (Moelyono dkk, 1983/ 1984: 70). Hal ini sesuai dengan apa yang disampaikan oleh Kramsch (1998: 3) dan Ahimsa-Putra (1986: 107) bahwa gagasan terhadap suatu keadaan atau fakta, 
pemikiran, cara pandang suatu masyarakat, sikap, kepercayaan,dan dasar penentuan cara pandang suatu masyarakat terhadap konsep kehidupan bisa disampaikan oleh pengguna bahasa melalui bahasa yang digunakannya, misalnya dari penamaanpenamaan suatu hal dalam ranah tertentu.

\section{KESIMPULAN}

Masyarakat Madura memiliki 49 metafora pengungkap kecantikan perempuan, yang terdiri dari 39 metafora pengungkap kecantikan fisik dan 10 metafora pengungkap kecantikan sikap perempuan. Jenis-jenis pembanding yang digunakan sebagai bentuk 49 adalah nama tumbuhan, peralatan, binatang, makanan, alam, dan lain-lain. Metaforametafora pengungkap kecantikan perempuan tersebut mencerminkan beberapa cara pandang masyarakat Madura, yaitu kecantikan fisik lebih mudah untuk diibaratkan atau dibandingkan dengan hal lain, tata krama perempuan Madura sangat ditekankan dan dijunjung tinggi kehadirannya, tidak semua konsep kecantikan berpatokan pada satu bentuk atau warna ideal suatu bagian tubuh tertentu, dan tumbuhan adalah sumber kehidupan, budaya, dan nilai-nilai praktik yang tinggi dalam masyarakat Madura.

\section{UCAPAN TERIMA KASIH}

Peneliti mengucapkan terima kasih banyak kepada Bapak Dr. Suhandono, M.A selaku dosen Ilmu Lingustik, Fakultas Ilmu Budaya, Universitas Gadjah Mada, utamanya sebagai dosen mata kuliah Linguistik Antropologi yang telah berkenan memberikan kritik dan saran selama pengerjaan penelitian ini.

\section{DAFTAR PUSTAKA}

Ahearn, L.M. (2012). Living language: An introduction to language anthropology. Wes Sussex: Wiley Blackwell

Ahimsa-Putra, H.S. (1986). "Etnosaind dan etnometodologi: sebuah perbandingan". Majalah Ilmu-Ilmu Sosial Indonesia XII (2): 103-102

Backer, dkk. (1965). Flora of Java (spermatophytes only). Vol. I. Groningen: N.V.P.Noordhoff

Bastari \& Yoesi, I.F. (2009). Kosakata bahasa Madura lengkap. Surabaya: Karya Simpati Mandiri.

de Jonge, H. (2011). Garam kekerasan dan aduan sapi. Yogayakarta: LkiS

Duranti, A. (1997). Linguistics anthropology. New York: Cambridge University Press 
Karim, A. D. (2004). Pemimpin wanita Madura. Surabaya: Papyrus

KBBI. (2016). KBBI daring. [online]. Diakses dari kbbi.kemdikbud.go.id (7 Juni 2017).

Kiliaan, H. N. (1904). Madoereesch-Nederlandsch woordenboek (Bag. 1). Leiden: E. J. Brill . (1905). Madoereesch-Nederlandsch woordenboek (Bag. 2). Leiden: E. J. Brill

Knowles\& Moon. (2006). Introducing metaphors. London dan New York: Routledge Taylor dan Francis Group

Kramsch, C. (1998). Language and culture. New York: Oxford University Press.

Kridalaksana, H. (1993). Kamus linguistik. Jakarta: Gramedia

Moelyono, dkk. (1983/ 1984). Mengenal sekelumit kebudayaan orang Madura di Sumenep. Yogyakarta: Departemen Pendidikan dan Kebudayaan Direktorat Jendral Kebudayaan Balai Kajian Sejarah dan Nilai Tradisional Yogyakarta.

Tilaar, M. (1999). Kecantikan perempuan timur. Magelang: IndonesiaTera.

Tim Penulis. (2004). Inner beauty, wonderful woman. Yogyakarta: Enigma Publishing. Palmer, G.B. (1999). Toward a theory of cultural linguistics. Austin: University of Texas Press

Saed, Jhon. I. (1999). Semantics. Blackwell: Cambridge

Setiadi. (2005). Korban menjadi korban: perempuan Madura pascakonflik Sambas. Yogyakarta: Kerja sama Ford Foundation dengan Pusat Studi Kependudukan dan Kebijakan, Universitas Gadjah Mada.

Setyari, A.D. (2007). Panyandra bentuk tubuh indah dalam masyarakat Jawa. [Tesis]. Yogyakarta: Sekolah Pascasarjana Fakultas Ilmu Budaya Universitas Gadjah Mada.

Sudaryanto. (1988). Metode linguistik: Bagian kedua, metode dan aneka teknik pengumpulan data. Yogyakarta: Sanata Dharma University Press. . (2015). Metode dan aneka teknik analisis bahasa: pengantar penelitian wahana kebudayaan secara linguistis. Yogyakarta: Sanata Dharma University Press. 
Nur Awaliyah Putri

Wibowo, H. J, dkk. (2002). Tata krama suku bangsa Madura. Yogyakarta: Badan Pengembangan Kebudayaan dan Pariwisata, Deputi Bidang Pelestarian dan Pengembangan Budaya, Balai Kajian Sejarah dan Nilai Tradisional Yogyakarta, Proyek Pemanfaatan Kebudayaan Daerah, Daerah Istimewa Yogyakarta.

Wolf, N. (2002). Mitos kecantikan: kala kecantikan menindas perempuan. Yogykarta: Penerbit Niagara. 